\title{
THE V CONGRESS OF THE RUSSIAN PSYCHOLOGICAL SOCIETY
}

\author{
Andrey L. Zhuravlev \\ Institute of Psychology of the Russian Academy of Sciences \\ Moscow, Russia \\ Yuri P. Zinchenko \\ Lomonosov Moscow State University \\ Moscow, Russia \\ Yuliya V. Kovaleva, \\ Elena A. Sergienko \\ Institute of Psychology of the Russian Academy of Sciences, \\ Moscow, Russia
}

This paper summarizes the organizational and scientific outcomes of the 5 th Congress of the Russian Psychological Society. It shows the RPS's dynamics of development since its establishment to the present day, and presents a report on the Congress's major events, and the statistics in comparison with the other events of international scientific life. Scientific sections of the Congress are grouped that allowed to showing the main trends in modern psychology. The new directions of psychological research debuted on the Congress are shown, the most important domains of the psychological science are highlighted, and possible reasons for some of them not having succeeded are given. The new subjects and objects of psychological studies new to psychologists are identified. Based on the historical view of the contemporary psychology, were analyzed the future directions of its development

Keywords: Russian Psychological Society, congress, history of psychology, development of psychology

The V Congress of the Russian Psychological Society (RPS) took place in Moscow on February 14-18, 2012. The history of the RPS began on January 24, 1885, when the first meeting of the Psychological Society of the Emperor's Moscow University was held. 
Today the RPS includes 58 regional departments located in most of the federal subjects of the Russian Federation.

1417 persons from 57 federal subjects of the Russian Federation, with theses of articles and speeches approved for publication, registered for participation in the V Congress of the Russian Psychological Society. There were 34 scientific directions of the Congress work, 125 section meetings and panel discussions were held. More than 900 Congress participants presented their reports.

Table 1 shows the comparison of some quantitative measures of the V Congress of the RPS, the IV Congress of the RPS and the XI European Congress of Psychology which took place in Oslo in 2009.

Table 1

Quantitative measures of the V Congress of the RPS, the IV Congress of the

RPS and the XI European Congress of Psychology (Oslo, Norway, 2009)

\begin{tabular}{|l|c|c|c|}
\hline \multicolumn{1}{|c|}{ Measure } & $\begin{array}{c}\text { XI European } \\
\text { Congress of } \\
\text { Psychology } \\
\text { (Oslo, Norway, 2009) }\end{array}$ & $\begin{array}{c}\text { IV Congress } \\
\text { of the RPS } \\
\text { (Rostov-on-Don, } \\
\text { September 2007) }\end{array}$ & $\begin{array}{c}\text { V Congress } \\
\text { of the RPS } \\
\text { (Moscow, } \\
\text { February 2012) }\end{array}$ \\
\hline Participants & over 2000 & 978 & 1417 \\
\hline $\begin{array}{l}\text { Scientific work } \\
\text { directions }\end{array}$ & 32 & 16 & 34 \\
\hline $\begin{array}{l}\text { Sections } \\
\text { locations }\end{array}$ & 4 & 3 & 8 \\
\hline
\end{tabular}

Table 2 demonstrates us the "portrait" of the V Congress of the RPS participants:

Table 2

\section{"Portrait" of the V Congress of the RPS participants}

\begin{tabular}{|l|c|c|}
\hline \multicolumn{1}{|c|}{ Category of participants } & $\begin{array}{c}\text { Number } \\
\text { of participants }\end{array}$ & $\begin{array}{c}\text { Average age } \\
\text { of participants }\end{array}$ \\
\hline $\begin{array}{l}\text { Doctors of science, professors, principal } \\
\text { and leading staff scientists }\end{array}$ & 324 & 59 \\
\hline $\begin{array}{l}\text { Candidates of sciences, associate } \\
\text { professors, senior staff scientists }\end{array}$ & 467 & 48 \\
\hline $\begin{array}{l}\text { Other participants, including students } \\
\text { and postgraduate students }\end{array}$ & 626 & 31 \\
\hline
\end{tabular}


The largest delegations at the V Congress of the RPS were represented by the members of the following RPS regional departments: Moscow department (344 participants), Saint Petersburg department (183), Rostov department (72), Yaroslavl department (46), Chelyabinsk department (38), Tomsk department (27), Samara department (26).

There were also participants from foreign countries at the Congress - both from the CIS (Belarus, Ukraine, Kazakhstan, Moldova, Azerbaijan, Uzbekistan, Armenia, Abkhazia) and other countries (the USA, Canada, France, Germany, Japan, Switzerland, Finland, Great Britain, Norway, Sweden, China, Vietnam).

The organizing committee was represented by:

- Chairman: Y. P. Zinchenko, corresponding member of the Russian Academy of Education

- Deputy Chairmen: doctor of psychological sciences (Psy.D.) D.B. Bogoyavlenskaya, Psy.D., professor M.K. Kabardov, Psy.D., professor O.A. Karabanova, corresponding member of the Russian Academy of Sciences A.V. Yurevich

- Members: corresponding member of the Russian Academy of Education I.V. Abakumova, Psy.D., professor G.V. Akopov, Psy.D., professor B.S. Alishev, academician of the Russian Authors' Society A.G. Asmolov, Psy.D., professor O.A. Akhverdova, Psy.D., professor T.Y. Bazarov, Psy.D., professor N.A. Baturin, Psy.D., professor K.I. Vorobyeva, academician of the Russian Academy of Education A.I. Dontsov, Psy.D., professor A.N. Gusev, Psy.D., professor T.A. Zhalagina, Psy.D., professor M.M. Kashapov, Psy.D., professor E.E. Kravtsova, Psy.D., professor T.L. Kryukova, corresponding member of the Russian Academy of Education D.M. Mallayev, candidate of psychological sciences V.V. Pchelinova, Psy.D., professor Z.I. Ryabikina, academician of the Russian Academy of Education D.I. Feldshtein, Psy.D., professor M.S. Yanitsky.

The Programme Committee was represented by:

- Chairman: corresponding member of the Russian Academy of Sciences A.L. Zhuravlev

- Deputy Chairmen: Psy.D., professor Y.M. Zabrodin, Psy.D., professor E.A. Sergienko, academician of the Russian Academy of Education V.S. Sobkin, academician of the Russian Academy of Education V.D. Shadrikov

- Scientific secretary: candidate of psychological sciences Y.V. Kovaleva 
- Members: Psy.D., professor V.M. Allakhverdov, Psy.D., professor Y.I. Aleksandrov, corresponding member of the Russian Academy of Education V.A. Barabanschikov, corresponding member of the Russian Academy of Sciences B.M. Velichkovsky, corresponding member of the Russian Authors' Society E.V. Galazhinsky, academician of the Russian Academy of Education A.A. Derkach, corresponding member of the Russian Academy of Education G.V. Zalevsky, academician of the Russian Academy of Education P.N. Yermakov, Psy.D., professor V.A. Kol'tsova, corresponding member of the Russian Academy of Education A.V. Karpov, corresponding member of the Russian Academy of Education S.B. Malykh, academician of the Russian Academy of Education N.N. Nechaev, corresponding member of the Russian Academy of Sciences V.F. Petrenko, Psy.D., professor L.M. Popov, Psy.D., professor V.E. Semenov, Psy.D., professor A.S. Chernyshev.

Scientific events (section meetings, panel discussions, poster discussions etc.) of the V Congress of the RPS were held at some of the leading scientific, educational and practical psychological centers of Moscow: the Faculty of Psychology of the Lomonosov Moscow State University (96 events), the Institute of Psychology of the Russian Academy of Sciences ( 3 events), the Institute of Psychology of the Russian Academy of Education (12 events), the Moscow State University of Psychology \& Education (8 events), the Center for emergency psychological help of the EMERCOM, Russia (2 events), the Russian Presidential Academy of National Economy and Public Administration (2 events), the Moscow City service for psychological aid to the population (1 event), the I.M. Sechenov First Moscow State Medical University (1 event).

Congratulations and greetings to the Congress participants were sent by:

- V.V. Putin - Prime Minister of the Russian Federation;

- S.E. Naryshkin - Chairman of the State Duma of the Federal Assembly of the Russian Federation;

- Y.S. Osipov - President of the Russian Academy of Sciences;

- A.A. Fursenko - Minister of Education and Science of the Russian Federation;

- V.M. Platonov - Chairman of the Moscow City Duma;

- L.A. Bokeriya - President of the All-Russian Social Organization "National Health League", director of the Scientific center of the Ba- 
koulev Center for Cardiovascular Surgery, academician of the Russian Academy of Sciences and the Russian Academy of Medical Sciences;

- Rainer Silbereisen - President of the International Union of Psychological Science under UNESCO;

- Robert Roe - President of the European Federation of Psychologists' Associations.

The following participants presented their speeches at the plenary meeting of the V Congress of the RPS:

- S.K. Shoygu, Minister of the EMERCOM of Russian Federation;

- V.A. Sadovnichy, Rector of the Lomonosov Moscow State University, academician of the Russian Academy of Sciences, professor;

- Y.P. Zinchenko, President of the Russian Psychological Society, dean of the Faculty of Psychology of the Lomonosov Moscow State University, corresponding member of the Russian Academy of Education, professor;

- L.A. Tsvetkova, the first Vice-President of the Russian Psychological Society, doctor of psychological sciences, associate professor;

- M.P. Kirpichnikov, Chairman of the Higher Attestation Commission of the Russian Federation, academician of the Russian Academy of Sciences, dean of the Faculty of Biology of the Lomonosov Moscow State University;

- I.M. Remorenko, State secretary, Deputy Minister of Education and Science of the Russian Federation;

- A.G. Asmolov, Head of the Department of Personal Psychology of the Lomonosov Moscow State University, Director of the Federal State Institution "The Federal Institute of Education Development", academician of the Russian Academy of Education, professor;

- V.V. Rubtsov, Rector of the Moscow State University of Psycho$\operatorname{logy} \&$ Education, academician of the Russian Academy of Education, professor;

- A.L Zhuravlev, Corresponding member of the Russian Academy of Sciences, director of the Institute of Psychology of the Russian Academy of Sciences, professor;

- D.V. Ushakov, Head of the Psychology and Psychophysiology of Creativity Laboratory at the Institute of Psychology of the Russian Academy of Sciences, corresponding member of the Russian Academy of Sciences, professor; 
- V.M. Allakhverdov, Head of the Saint Petersburg department of the Russian Psychological Society, Head of the General Psychology Department of the Saint Petersburg State University, professor;

- N.N. Nechaev, Provost of the Moscow State Linguistic University, academician of the Russian Academy of Education, professor;

- Y.S. Shoygu, Director of the Center for emergency psychological help of the EMERCOM of Russian Federation.

An exhibition of professional achievements of practical and experimental psychology "Psychologists - to Russia" was held on February 14 - the opening day of the V Congress of the RPS. It presented hardware and software systems, techniques of diagnostics and correction of mental disabilities and states, including polygraph, a biofeedback system, the only virtual reality system in Russia, technologies of multivariable estimation, diagnostics and correction of stress, the "Children Online" support line and many other exhibits.

Universities and companies from many cities and regions of Russia took part in the exhibition: the Saint Petersburg State University and its Department of Psychology, the "Imaton" Company (Saint Petersburg), the Bashkir State University (Ufa city), the "Medikom" Company (Taganrog city), the Department of Psychology of the Southern Federal University (Rostov-on-Don city), the Department of Psychology of the Tomsk State University (Tomsk city). The Moscow region was represented by the Faculty of Psychology of the Lomonosov Moscow State University, the Moscow State University of Psychology \& Education, the Center for emergency psychological help of the EMERCOM of Russia and the "Neyrobotiks" Company (Zelenograd city). Publishing companies "Smysl" and "Aspekt-Press", well-known among the psychologists, participated in this exhibition as well.

On February 15 a press conference dedicated to the V Congress of the RPS in Moscow took place at the Russian Information Agency (RIA) "Novosti" press centre.

The press conference participants - Y.P. Zinchenko, V.V. Rubtsov, L.A. Tsvetkova, E.V. Galazhinsky, Y.S. Shoygu, A.G. Asmolov, P.N. Yermakov and others - specified the modern tendencies of development of psychological knowledge and its application in various practical areas. Particularly, the increased fastness of living, development of informational and communication technologies, increase of uncertainty, en- 
hancement of migration flows, increase of the number of industrial disasters, terrorism and emergency situations issue new challenges for the psychologists - both scientific and practical tasks that are determined by the risk society. Eminent scientists discussed the following actual problems. How to solve the above-mentioned problems of modern research and practical psychology? Doesn't the necessity of quick reaction to the demands of society lead to lowering of the role of the humanistic component of the modern psychology? Does extreme time require extreme people? Should psychology take both research and political tasks upon itself? What transformations occur to people and culture in the risk space? What are the psychological peculiarities of the "digital" generation in Russia? What is the role of psychologists in the process of development of the New School and modern educational standards? Can tolerance become a tool for counteracting xenophobia?

On February 16, 2012 an interdisciplinary panel discussion "Intellectual Rights in Psychology" was held at the Faculty of Psychology of the Lomonosov Moscow State University. There were both psychologists (researchers, practitioners, developers of practical tools) and representatives of the jurisprudential community among its participants. The problems of qualification of protected intellectual rights in psychology, specific character of intellectual rights in different spheres of practical psychology (psychodiagnostics, educational activities, psychotechnologies creation etc.), potential for intellectual rights protection in psychology (including the rights for newly created products) were brought up at the panel discussion.

Several editions were published specially for the V Congress of the RPS: a collective monograph about L.S. Vygotsky (in French), a special issue of the "National Psychological Journal" (Natsionalny Psikhologichesky Zhurnal"), theses of reports and speeches that were presented at the Congress.

Some important documents were approved during the Congress works:

- Code of Ethics for Psychologists

- Ethical Principles of the Russian Psychologists' Work

- The Russian Psychologist's Oath.

The Russian Psychologist's Oath is as follows:

While receiving a high rank of a Russian psychologist and starting my professional activity, I do solemnly declare: 
- to fulfill my professional duties in compliance with the ethical principles of the Russian psychologists' work;

- to devote my knowledge and skills to preserving and strengthening people's psychological health and wellbeing;

- to be ready to provide psychological help at any time;

- to show the highest respect for human life, rights, wellbeing and dignity;

- to stay grateful and respectful towards my teachers;

- to be exigent and fair towards my students, to assist them in their professional growth;

- to treat my colleagues with benevolence;

- to search for my colleagues' assistance and advice if it is required by the interests of the person who asks for my help;

- and, in my turn, never to deny assistance and advice to my colleagues;

- to improve my professional skills constantly;

- to keep and develop the glorious and noble traditions of the Russian psychological science;

- May I be pure in my deeds and thoughts, may I never break this oath.

It was emphasized in the framework of discussion that compliance of the Russian educational standards with the European qualification standard for psychologists (EuroPsy) is of great importance. The EuroPsy mandatory requirements include:

- Academic education in psychology of five years or more

- At least one year of practice under the supervision of a qualified supervisor

- Compliance with a statement on ethical conduct and ethical principles of practice

- Proper use of psychodiagnostic techniques

A Resolution was adopted on the basis of the V Congress of the RPS results. Its fundamental provisions - the necessity of which was emphasized at the Congress - are given below:

- Increase of the role of psychological science in social governance;

- Development of Russian scientific schools and creation of innovative promising development directions for psychological science and practice; 
- Development of standards and ethical principles of professional activities for practicing psychologists;

- Certification of practicing psychologists, creation of an All-Russian Register of Certified Psychologists;

- Maintaining education by speciality as the basic path of psychologists' education;

- Analysis of achievements and development tendencies of Russian psychology. Such analysis allows us to determine the mission of the Russian Psychological Society as the task of increasing the role and status of the psychological science and practice in the process of the modern Russian society governance;

- Acceleration of the process of establishing - within the framework of the Russian Psychological Society - sections the activities of which correspond to the spheres of psychology that have accumulated abundant experience in solving actual social problems and exercised such initiative in accordance with the RPS Statutes;

- To apply to the Government of the Russian Federation for the necessity of development of Federal Law "On psychological aid to the population" project; forming a work group for development of Federal Law "On psychological aid to the population" project;

- Development of uniform standards for professional activities of psychologists, including consulting psychologists, developmental psychologists, family psychologists, sports psychologists etc., and making of corresponding job descriptions for the purpose of adding them to the Unified Skills Guide for Positions of Managers, Specialists and Nonmanual workers;

- Development of the specialists-psychologists facultative certification project, including a unified form of certificate confirming the right to perform professional activities; creation of the Unified Register of Certified Psychologists;

- Creation (together with the representatives of a professional jurisprudential community) of a work group for the purpose of studying the issues connected with protection of intellectual rights in psychology, opportunities in the sphere of audit of methodological materials, diagnostic and corrective tools;

- In connection with preparation for effectiveness of a Federal Law № 436 of 29.12.2010 "On the Protection of Children from Information Harmful to Their Health and Development", for the purpose of 
ensuring information security of children and youth, to combine efforts of specialists in different spheres of knowledge and practice (psychologists, educators, doctors, journalists, jurists, sociologists etc.) in order to develop ways, technologies and methods for age-related classification of information products on the basis of the RPS as a social organization. To elaborate (together with the representatives of the Ministry of Communications and Mass Media of the Russian Federation) requirements and recommendations for the forming of a council of experts on the issues of information and psychological security of children and youth;

- To apply to the Ministry of Education and Science of the Russian Federation and the State Duma of the Russian Federation for alteration of the Federal Law "On Education" and adding a mandatory provision of establishing a psychological service in each educational institution and organization, its provision with methodological materials and resources.

Analysis of the scientific program of the V Congress of the RPS, in spite of its breadth and diversity, allowed us to determine several generalized lines that act as centers of grouping and development of particular psychology spheres.

34 scientific directions can be conventionally classified into the following 4 main groups:

1. Actual problems of theoretical psychology and psychological practice. They include such directions as:

- Methodology and history of psychology

- The cultural activities paradigm of constructivism

- Modern programs, methods and techniques in research and applied psychology

- Psychological practice

- Psychodiagnostics

- Consulting psychology and non-clinical psychotherapy

2. Modern researches in different spheres of psychology. They include:

- Psychology and psychosemantics of consciousness. Psychology of speech

- Developmental psychology and acmeology

- Psychophysiology

- Psychogenetics 
- Cognitive psychology

- Zoopsychology and comparative psychology

- Psychology of security and military psychology. Psychology of extreme activities.

- Judicial psychology and psychology of law enforcement activities

- Sports psychology

- Health psychology and clinical psychology

- Ethical psychology and moral psychology

3. Modern personality psychological problems. This group includes the following directions:

- Psychology of personality and individuality

- Psychology of abilities, intellect, talent and creativity

- Psychology and religion

- Existential psychology

- Psychology of regulation and self-regulation

4. Modern society psychology and problems. This group unites three subgroups:

a) Psychology and social environment

- Social and political psychology

- Communication psychology

- Ethnical and cultural psychology

- Psychology of modern megalopolis

- Psychology of modern family

b) Psychology and education

- Educational psychology. New standards of psychological education

- Pedagogical psychology

- Psychological and pedagogical problems of education

- Development of abilities in educational and professional activities

c) Psychology and profession, business and economy

- Psychology of labor, engineering psychology and ergonomics

- Organizational psychology

- Economic psychology. Psychology of entrepreneurship. Psychology of advertising

This classification does not have a unified basis; however, it allows us to see a number of modern tendencies in development of different 
psychology spheres. For example, groups 1 and 2 reflect the psychologists' attention to the internal problems of psychology - evolution of the science of psychology in general or evolution of its particular spheres. Groups 3 and 4 demonstrate the advancement in the study of basic objects of psychology - individual, personality, interpersonal attitudes, intergroup attitudes, group, organization, society.

We can also specify the new scientific directions which were discussed at the V Congress of the RPS. They include both independent scientific directions and parts of combined directions:

- Psychology of modern megalopolis

- Psychology of security. Psychology of extreme activities.

- Existential psychology

- Ethical psychology

- Cultural psychology

- Psychology of entrepreneurship

- Psychology of advertising

- Health psychology

- Consulting psychology

- Non-clinical psychology

- Internet psychology

These research and practical directions indicate the interest and attention of the science of psychology to a broad range of problems connected with a person's search for his place in the modern world - in the modern economic environment, the new information environment, the quickly changing conditions of living in urban environment, connected with the person's attempts to comprehend the profound basics of being. Formation of such a research and practical direction as "Consulting Psychology" indicates the evolution of psychological science itself, its continuous search for new research objects and practical spheres of psychology knowledge application.

Appearance of these new scientific directions is considered to be one of the evident signs of modern psychology development. Of course, such researches were conducted in the past as well, but at the V Congress of the RPS they established themselves as independent scientific directions for the first time.

Formation of such a research and practical direction as "Non-clinical psychotherapy", combined with "Consulting psychology", actually indicated the end of a prolonged dispute between psychologists and psy- 
chiatrists over the right to conduct psychotherapeutical practice. Those psychiatrists who have completed medical education - and thus have a right to provide treatment - can practice both clinical and non-clinical psychology. Psychologists can practice only theist non-clinical form that is, provide consultations to healthy people. It is a great achievement for psychologists!

When speaking about the new branches of psychology, we should also mention the specific character of the social psychology development that could be observed during the previous two decades. This specific character lies in the formation of a number of particular socially oriented directions in psychology which were formerly united in social psychology. Here are some of these new directions:

- Family psychology

- Communication psychology

- Economic psychology

- Organizational psychology

- Political psychology

Their active independent development allows us to speak about the formation of a system of sociopsychological directions and even branches at the modern stage of psychology evolution.

The basic criteria for determining the major scientific directions represented at the V Congress of the RPS were: the number of events in their framework (symposiums, meetings, panel discussions etc.) and the number of participants (50-100 persons). The major directions were the following ones:

- Methodology and history of psychology

- Developmental psychology and acmeology

- Psychology and psychosemantics of consciousness. Psychology of speech

- Psychology of abilities, intellect, talent and creativity

- Clinical psychology

- Social and political psychology

- Communication psychology

- Organizational psychology

- Ethical and cultural psychology

- Psychology of modern family

- Psychophysiology 
It is possible to specify the directions which are traditionally of great interest for the professional psychologists' community. They include:

- Methodology and history of psychology

- Psychology of personality and individuality

- Psychology of abilities, intellect, talent and creativity

- Psychology and psychosemantics of consciousness. Psychology of speech

- Developmental psychology and acmeology

- Social psychology

- Clinical psychology

- Psychophysiology

- Psychological practice

Analysis of the published works at the Congress allowed us to determine the new topics and objects of researches conducted by the Congress participants. They reflect the tendencies in both the particular directions and in the science of psychology in general. Their degree of novelty can be estimated in different ways.

The direction "Methodology and history of psychology" is represented by the following new topics: empathy, children's lies, nucleus of community, genius, mode of life.

The direction "Psychology and psychosemantics of consciousness": consciousness, preference, time. A new topic - cinema discourse - is also being studied within the framework of the "Psychology of speech" direction.

The "Developmental psychology" researchers studied such objects as elderly people, married couples, teenagers as Internet users, autistic children. The new topics of study included: the name of a person, partnership relationships, graphic concept, collective regulation of behavior, time reflection, social subjectness of mature age women, cognitive age and so on. Within the "Acmeology" direction a new approach to the study of scientific problems arose - it is called "ethnoacmeology".

The new topics of researches in the framework of the "Psychology of personality and individuality" direction include: life scenario, maturity, conscience, ambition, holiday, self-description, attitude towards death, personality of a terrorist, media behavior of a person, viability, self-presentation of gender, civil identity, human endeavors, time perspective, "personal threat", sexual identity, personality compensation, existential self-realization. 
The new research topics of the "Psychology of abilities, intellect, talent and creativity" direction include: artistic talent, psychological barriers of innovative development, intellectual competence, conceptual framework and so on.

Among the new research topics of the "Psychology of regulation and self-regulation" are the mental state mode and humor.

Studies of the "Psychology of labor, engineering psychology and ergonomics" examined such new topics as reorganization shock, professional identity, career orientation, concept of professional environment, professional's personality health, creative age. The new objects of researches were: substituting parents, the State Inspection for Road Traffic Safety employees, unemployed people.

The new research objects of the "Organizational psychology" direction were business coaches and virtual organizations, and its new topics included hospitality, employees' normative deviation, employees' psychological capital, personnel loyalty.

The relatively new topics of research in the framework of the "Economic psychology. Psychology of entrepreneurship. Psychology of advertising" direction included the attitude towards bribe, money image, economic activity.

The new topics of the "Ethical psychology and moral psychology" direction are envy and consciousness, moral self-identification, altruistic choice.

A wide range of new research topics formed within the "Social and political psychology" direction: concepts of enemies and friends, destructive leadership, concept of "modern world", time strategies, concept of happiness, rumors formation, childfree phenomenon, psychological culture, socio-psychological environment, ageist stereotypes, sexuality as socio-psychological phenomenon, time competence, media impact, tolerance for uncertainty, social capital, maturity of a group, lookism, self-restriction, love patterns in human life cycle, virtual communications, ecological values.

Within the framework of the "Ethnical and cultural psychology" direction the researchers studied the following new objects: spouses in biethnic marriage, biethnic family, participants of bullying behavior. The new research topics included: interethnic perception, ethnopsychological subjects, ethnotrauma, intercultural competence. 
A new research topic - biosocial nature of security - can be specified within the "Psychology of security and military psychology" direction. The "Psychology of extreme activities" also has a new object of researches - football hooligans.

New objects were also formed within the "Judicial psychology and psychology of law enforcement activities" - extremist materials, suicide terrorists. The new research topic of this direction is age as phenomenon and category of judicial psychology.

The "Health psychology and clinical psychology" was represented by the following new topics: Internet addiction, attitude towards mentally ill people, individual concept of appearance.

The "Zoopsychology and comparative psychology" researchers studied nonverbal communication methods of people and animals.

The new direction "Psychology of modern megalopolis" was represented by the following new research topics: visual culture, paternal deprivation, ecological behavior, perception, concepts, attitude towards city environment images (architecture) and a new object - matriculants from monoethnic regions.

The "Psychology of modern family" direction demonstrated such new topics as family history, intergenerational interaction, structure of parental concepts, and a new object - substituting parents.

The "Modern programs, methods and techniques in research and applied psychology" studied a new object - blogs (online diaries) - and a new topic - professional's innovative potential. The research works of the participants were also dedicated to the new methods - online testing, qualitative studies, netnography.

The researchers of the "Psychological practice" directions examined the use of Internet technologies in consulting.

The "Psychodiagnostics" direction was represented by the following new research topics: diagnostics of perfectionism and time perspective.

The new topics of the "Development of abilities in educational and professional activities" are the teacher's abnotivity and moral skills.

Within the framework of the "Psychology and religion" the new topics included religious extremism (in the youth environment of the Northern Caucasus), spiritual needs, spiritual motives, state of consciousness, professionally important characteristics of a pastor.

The "Existential psychology" (a new direction at this Congress) was represented by the following topics: existential resources, self-impor- 
tance, time limitedness, co-existence, co-existentiality, existential experience, ontological certainty, self-interpretation.

The "Communication psychology" direction showed such new research topics as private communication, media communication, mass media language, identification response in the process of TV programs perception and virtual communication.

The above-mentioned novelties reflect a number of processes that are happening in the psychological science at the modern stage. First of all, we should mention its focus on actual problems of social importance. It is indicated by the new topics and objects connected with such important social problems as terrorism and extremism, drug addiction and alcoholism. The range of actual problems also includes Internet and telecommunication issues and other topics.

It is interesting enough that among the prevailing, interdisciplinary topics at the modern stage there are time, age (subjective time, subjective age, time perspective) and related different types of growing up and maturity. These topics were studied by researches within the framework of the following directions: cognitive psychology, developmental psychology and acmeology, psychology of regulation and self-regulation, moral psychology, psychology of labor, historical and social psychology, psychology of extreme activities, judicial psychology, psychodiagnostics, existential psychology etc. Evidently, the modern psychology, as well as the modern person, is going through a period of individual and social changes which happen to time both in individual and social context and it conditions the necessity of making steps towards comprehension and study of these processes.

Among the scientific directions of the V Congress of the RPS we can mark out those ones that were connected with practical problems mostly. The criteria for determining such directions were their summary programs that had practical orientation connected both with the actual social problems and the problems of development of the particular direction itself and its ability to answer different practical demands and challenges.

Several panel discussions were held within the "Health psychology and clinical psychology" direction. They were dedicated to the following issues: professional training and professional status of clinical psychologists at the modern stage, alcoholism, drug addiction and other forms of addiction behavior, methodological and organizational aspects 
of problem situations in the diagnostics of psychological development disorders, research and organizational models of psychoprophylaxis. The problem of psychological support of the processes of mastering medical professions was also brought up at the panel discussion of the "Educational psychology. New standards of psychological education" direction. The issues of providing psychological aid to population were brought up at the "Psychological practice" direction panel discussion which was held together with the Moscow City service for psychological aid to the population of the Moscow Department for Families and Youth Policy.

The "Psychology of modern family" panel discussions studied the problems of families and children from the risk group, and also the issues connected with practical activities and professional training of family psychologists. A joint panel discussion with the "Psychogenetics" direction was dedicated to the study of individual differences in the family. Family and childhood problems were also brought up at the panel discussions of other directions. For example, the "Communication psychology" paid attention to the issues of children and youth protection from the negative impact of mass media, and the "Developmental psychology and acmeology" panel discussion considered the problem of professional training in the sphere of perinatal psychology.

The "Psychology and religion" and the "Ethical psychology and moral psychology" panel discussions participants talked about the actual problems of interaction between psychology and religion, including the issues of content of the moral and ethical psychology as a subject.

The relations between people, cities and environment were discussed at the event held in the framework of a new direction - "Psychology of modern megalopolis".

The "Social and political psychology" and the "The cultural activities paradigm of constructivism" panel discussions touched upon the issues of profound social problems connected with conflict and consent in socio-psychological environment and also with tolerance and management of xenophobia risks in the modern society.

The "Organizational psychology" panel discussions were dedicated to a wide range of issues connected with business and professional training - that is, personnel management, specialists training and certification in this sphere, actual and perspective problems of interaction 
between the modern organizational psychology and Russian company executives and company owners.

Against the background of increased interest in the problems connected with mass media and Internet the themes of the "Psychology of speech" panel discussions dedicated to the reading development problems were especially prominent.

The "History and methodology of psychology" direction panel discussion can be considered a final summary of this analysis. It was focused on comprehension of the problems of interaction between theoretical and experimental researches and practice in psychology at the modern stage of its development.

Analysis of the scientific program of the Congress allows us to see the perspectives of psychology. On the basis of a number of scientific criteria we can conclude that the science of psychology continues its active evolution. The criteria of its evolution include, among the others, the differentiation/integration of different scientific directions and spheres. Several psychological directions are characterized by a tendency for delimitation, concretization and detailing of the research topics. At the same time, a number of directions demonstrate an opposite trend for convergence of the problems studied, partial intersection of the range of topics and problems of researches.

These are some examples of differentiation of scientific directions and spheres in modern psychology:

- "Pedagogical psychology" was divided in two directions - "Pedagogical psychology" and "Psychological and pedagogical problems of education". In addition, a new direction was presented: "Educational psychology. New standards of psychological education".

- "Psychology of abilities" was represented by several directions: "Psychology of abilities, intellect, talent and creativity", "Development of abilities in educational and professional activities".

The following events are the examples of scientific directions integration:

- an interdisciplinary panel discussion "Interaction between fundamental psychology and psychological practice";

- joint events within the framework of the "Psychology of modern family" and "Psychogenetics" directions; 
- a joint panel discussion within the "Educational psychology" and "Psychology of health and clinical psychology" directions;

- an interdisciplinary panel discussion dedicated to the problems of intellectual property.

The analysis of the scientific program of the V Congress of the RPS allows us to show the historical section of the modern Russian psychology, its groundwork and perspectives as a branch of science, and also the active participation of psychology in the process of searching for solutions to social problems and its potential in fulfilling various socially important tasks. 